\title{
Health-related quality of life in elderly diabetic outpatients in Vietnam
}

This article was published in the following Dove Press journal:

Patient Preference and Adherence

\section{Huong Thi Thu Nguyen ${ }^{1,2}$ \\ Mackenzie PI Moir ${ }^{3}$ \\ Thanh Xuan Nguyen ${ }^{2,4}$ \\ Anh Phuong $\mathrm{Vu}^{5}$ \\ Long Hoang Luong 2,4 \\ Tam Ngoc Nguyen ${ }^{1,2}$ \\ Long Hoang Nguyen ${ }^{6}$ \\ Bach Xuan Tran ${ }^{7,8}$ \\ Tung Thanh Tran 9 \\ Carl A Latkin ${ }^{8}$ \\ Melvyn WB Zhang ${ }^{10}$ \\ Roger CM Ho"l \\ Huyen Thanh Thi Vu ${ }^{1,2}$ \\ 'Department of Gerontology, Hanoi Medical University, Hanoi, Vietnam; \\ ${ }^{2}$ National Geriatric Hospital, Hanoi, Vietnam; ${ }^{3}$ School of Public Health, \\ University of Alberta, Edmonton, $A B$, Canada; ${ }^{4}$ Dinh Tien Hoang Institute of Medicine, Hanoi, Vietnam; ${ }^{5} \mathrm{Hanoi}$ Medical University, Hanoi, Vietnam; ${ }^{6}$ School of Medicine and Pharmacy, Vietnam National University, Hanoi, Vietnam; ${ }^{7}$ Institute for Preventive Medicine and Public Health, Hanoi Medical University, Hanoi, Vietnam; ${ }^{8}$ Bloomberg School of Public Health, Johns Hopkins University, Baltimore, MD, USA; ' Institute for Global Health Innovations, Duy Tan University, Da Nang,Vietnam; ${ }^{10}$ Biomedical Global Institute of Healthcare Research \& Technology (BIGHEART), National University of Singapore, Singapore; "Department of Psychological Medicine, Yong Loo Lin School of Medicine, National University of Singapore, Singapore}

Correspondence: Huong Thi Thu Nguyen Department of Gerontology, Hanoi Medical University, 0 I Ton That Tung, Hanoi, II 5000 , Vietnam

Tel +8497305 6334

Email thuhuonglk@hmu.edu.vn
Background: Health-related quality of life (HRQoL) is an important indicator for designing care and treatment services for patients with diabetes. This is especially true given its rapid increase among the elderly population in Vietnam. HRQoL data in elderly diabetic Vietnamese are currently limited. This study aimed to 1) measure the HRQoL of elderly patients with type 2 diabetes (T2DM) in Vietnam and 2) identify related factors and their relationship with HRQoL.

Patients and methods: A cross-sectional study was conducted. We recruited 171 patients aged $\geq 60$ years with T2DM at the Outpatient Department, National Geriatric Hospital from June to November 2015. Patients were asked to evaluate their health status using the EuroQol Five Dimensions Three Levels (EQ-5D-3L) and the Visual Analog Scale (VAS). Sociodemographic, diabetic treatment, and management characteristics were collected. Multivariate Tobit regression was used to determine which factors were associated with HRQoL, and the strength of this relationship.

Results: Patients reported some problems in all areas of the EQ-5D: pain/discomfort (50.9\%), mobility (33.3\%), anxiety/depression (24.0\%), usual activities (21.1\%), and self-care (10.5\%). The mean EQ-5D index score was 0.80 ( $\mathrm{SD}=0.20)$, and the mean EQ-VAS was $57.5(\mathrm{SD}=14.4)$. Patients who were male, lived in an urban area, could afford treatment, were taking fewer medications, and monitored blood pressure often (1-4 times a week) had a higher EQ-5D index when compared to other groups. Meanwhile, a longer duration of diabetes and older age were negatively associated with the EQ-5D index. Patients with any comorbidity had lower VAS scores than their counterparts.

Conclusion: The presence of diabetes and comorbidity were responsible for a significant decrease in HRQoL. Screening and identifying health problems, providing prompt treatment, and facilitating self-management among patients have the potential to increase diabetic patients' HRQoL.

Keywords: elder, quality of life, diabetes, Vietnam

\section{Introduction}

Population aging is an emerging problem of priority on the global health care policy agenda. ${ }^{1}$ The aging of the Vietnamese population has been accelerating in recent years, with substantial increases in the elderly population (aged $\geq 60$ years) in both relative and absolute numbers. ${ }^{1}$ It is estimated that the percentage of elder people will rise to over $30 \%$ in 2050 from $8.9 \%$ in $2009 .{ }^{1,2}$ Ensuring sufficient care and treatment provision as well as social supports for this population has become a major challenge to the Vietnam Government. ${ }^{3,4}$

Health-related quality of life (HRQoL) is considered an important indicator of health issues and health care needs in the elderly. ${ }^{5-7}$ Information about HRQoL can also 
be used to evaluate the performance of health care services, particularly when the availability of administrative data is limited. ${ }^{7,8}$ It can also be used to economically evaluate the effectiveness of health technologies and treatment. ${ }^{7,9} \mathrm{HRQOL}$ data are therefore needed in order to develop interventions and conditions favorable to the promotion of HRQoL.

Diabetes is increasingly common in low- and middleincome countries such as Vietnam. It is estimated that in 2015, over 3.5 million Vietnamese adults were living with diabetes. ${ }^{10}$ The prevalence of diabetes is especially high among the elderly. Pham and Eggleston showed that $12.8 \%$ of males and $10.9 \%$ of females living in Thai Nguyen over the age of 60 years had diabetes. ${ }^{11}$ Type 2 diabetes mellitus (T2DM) is the most common form of metabolic disorder in Vietnam, with a prevalence that has doubled in the previous decade $(2.7 \%$ in 2002 to $5.4 \%$ 2012). ${ }^{12,13}$ T2DM is disproportionally prevalent in different geographic regions throughout Vietnam. ${ }^{14,15}$ For example, in 2008, the rate of diabetes was more than $11 \%$ in Ho Chi Minh City, which is the biggest city in Vietnam, ${ }^{16}$ but less than $1 \%$ in rural Vietnam. ${ }^{17}$

Most patients with T2DM in Vietnam receive care on an outpatient basis, with hospital visitation used for regular physical assessment and management of complications. Elderly T2DM patients often suffer from comorbidities and geriatric syndromes that contribute to the development of frailty, defined as the cumulative decline of multiple physiological functions (eg, muscle weakness, low gait speed, etc.). ${ }^{18,19}$ The combination of diabetes and comorbidity can increase the likelihood of adverse outcomes, such as falls, disability, death, and hospitalization, ${ }^{19,20}$ all of which can significantly impair a patient's quality of life. ${ }^{21-23}$ Moreover, geriatric syndromes are a major obstacle when providing treatment and care to diabetic patients. ${ }^{18,22,24}$ Therefore, it is necessary to investigate the HRQoL of these patients, and associated factors, so that interventions designed to improve HRQoL can be developed and deployed.

Evaluations of HRQoL in elderly diabetic populations have been conducted worldwide in Asia, ${ }^{25,26}$ Europe, ${ }^{27-30}$ and the USA. ${ }^{31}$ Determinants of HRQoL have been found to vary across studies. Most have found correlations between HRQoL and sex, age, capacity to pay for treatment, occupations, income, body mass index (BMI), comorbidities (cardiovascular diseases, neuropathy, etc.), and treatment modalities like insulin or exercise..$^{25,27,28,30,32}$ However, few evaluations of HRQoL in diabetic populations have been completed in resource-scarce settings like Vietnam. Therefore, the objective of this study was to measure the HRQoL of elderly patients with T2DM in Vietnam and identify its covariates.

\section{Patients and methods Study design}

A cross-sectional study was conducted from July to November 2015 at the Outpatient Department, National Geriatric Hospital. A convenience sampling approach was used to recruit patients. To participate in the study, all subjects had to be 1) aged 60 years and older, 2) diagnosed with diabetes according to diagnostic criteria set out by the International Diabetes Federation in 2013,3) undergoing treatment as an outpatient at the National Geriatric Hospital, and 4) able to communicate with the data collector. Patients were excluded if 1) they were unable to complete the questionnaire and 2) they refused to participate in the study. A sample of 171 patients was recruited.

\section{Measures and instruments}

A structured questionnaire was developed and used for 25-min face-to-face interviews. Data collectors were students who were enrolling in undergraduate medical doctor and nursing degrees at Hanoi Medical University. To avoid social desirability bias, we did not use physicians and nurses employed at the hospital research site for collecting data. We conducted several training sessions for data collectors to ensure that they asked questions consistently and obtained high-quality data. The questionnaire included the following variables.

\section{Primary outcomes}

HRQoL was measured using EuroQol Five Dimensions Three Levels (EQ-5D-3L), ${ }^{25}$ which consists of five dimensions: mobility, self-care, usual activities, pain/discomfort, and anxiety/depression. Each dimension has three levels of responses: level 1; no problems; level 2: some problems; level 3: extreme problems. Health states were converted into a weighted index by applying scores from the UK utility tariffs set due to the unavailability of a Vietnamese tariff. ${ }^{33}$ The EQ-5D index score ranged from -0.594 to 1 , with a higher index depicting better HRQoL. ${ }^{33}$ We also employed the EQ Visual Analog Scale (EQ-VAS) to record the participant's self-rated health on a vertical scale that ranges from 0 to 100 . Zero represents the worst health state a patient can imagine and 100 represents the best health state a patient can imagine.

\section{Covariates}

Sociodemographic and behavior characteristics included age, sex (male/female), education attainment that was classified into three categories (low education: lower high school; medium education: graduate high school; high 
education: tertiary education), living location (urban/rural), people living with family/relatives/others/alone, who their primary informal caregiver was (family/relatives/others/ none), the ability to pay for treatment (yes/no), smoking status (yes/no), and if they were a current alcohol user (yes/no).

We measured the weight and height of participants to calculate their BMI. We used three BMI categories: $<18.50 \mathrm{~kg} / \mathrm{m}^{2}$ (underweight), $18.5-24.99 \mathrm{~kg} / \mathrm{m}^{2}$ (normal), and $\geq 25.00 \mathrm{~kg} / \mathrm{m}^{2}$ (overweight/obesity). Moreover, information on comorbidities was given by patients' self-reported data and confirmed by investigator based on medical records and medication utilization.

We also collected data on patients' diabetes treatment characteristics such as their disease duration, treatment modality (oral anti-diabetic drug, insulin, both or doing exercise only), number of medicines, whether they forgot to take medicine in the last 4 weeks (yes/no), fasting plasma glucose (mmol/L), and HbA1c (\%) level. Glycemic goals for adults with diabetes were achievement of fasting plasma glucose $\leq 7.2 \mathrm{mmol} / \mathrm{L}$ and $\mathrm{HbA} 1 \mathrm{c}<7 \%$. ${ }^{34}$ Other characteristics such as self-monitoring of blood glucose at home (yes/no), frequency of blood pressure monitoring and exercises, diet modification (yes/no), and if patients had ever delayed an examination were also collected.

\section{Data analysis}

Data analysis was performed using STATA 12.0 software (Stata Corp. LP, College Station, TX, USA). First, we described variables by using frequency and percentage for categorical variables, and mean and standard deviation for continuous variables. Multivariate regression was used to identify the factors associated with the EQ-5D index and EQ-VAS. Because the outcome data were censored data, we employed Tobit regression (or censored regression) model to have better estimation compared to typical linear regression. Stepwise forward selection strategies were used to produce the reduced model. These strategies selected variables into the final models using the threshold of $p$-value at 0.2 for the log-likelihood ratio test. Statistical significance was defined as any $p$-value less than 0.05 .

\section{Ethics approval and informed consent}

The study was approved by the National Geriatric Hospital Research Ethics Committee (No 794 NGH IRB). Written informed consent, which was approved by the Research Ethics Committee of the National Geriatric Hospital, Hanoi, Vietnam, was obtained from all participants in this study prior to data collection.

\section{Results}

Among 171 patients, the mean age was 69.4 years $(\mathrm{SD}=6.8)$. The majority of the patients were females (58.5\%), had a medium education (35.1\%), lived in an urban area (94.7\%), and lived with family (93.6\%). Most of them were taken care by their families $(94.2 \%)$ and were able to pay for diabetes treatment $(81.9 \%)$. In addition, $93 \%$ of patients had comorbidities. The mean EQ-5D index was $0.80(\mathrm{SD}=0.20)$, and the mean EQ-VAS was 57.5 ( $\mathrm{SD}=14.4)$ (Table 1).

Table 2 depicts that most of the patients had a diagnosis that was over 10 years old (49.1\%). The most common treatment modality was oral medications $(50.3 \%)$. More than five oral prescriptions were prescribed to $45.6 \%$ of patients for diabetes mellitus or other comorbidities. The average fasting plasma glucose was $7.8 \mathrm{mmol} / \mathrm{L}(\mathrm{SD}=2.2)$ and $\mathrm{HbA} 1 \mathrm{c}$ was $7.1 \%(\mathrm{SD}=1.5 \%)$.

Self-management of respondents is shown in Table 3. Most respondents performed self-monitoring blood glucose

Table I Socioeconomic and behavior characteristics of respondents

\begin{tabular}{|c|c|c|}
\hline & $\mathbf{n}$ & Percentage \\
\hline Total & $17 \mid$ & 100.0 \\
\hline Sex, female & 100 & 58.5 \\
\hline \multicolumn{3}{|l|}{ Education attainment } \\
\hline Low education & 57 & 33.4 \\
\hline Medium education & 60 & 35.1 \\
\hline High education & 54 & 31.6 \\
\hline \multicolumn{3}{|l|}{ Living location } \\
\hline Urban area & 162 & 94.7 \\
\hline Rural area & 9 & 5.3 \\
\hline \multicolumn{3}{|l|}{ Living with } \\
\hline Family & 160 & 93.6 \\
\hline Alone & 7 & 4.1 \\
\hline Others & 4 & 2.3 \\
\hline \multicolumn{3}{|l|}{ Being taken care by } \\
\hline Family & 161 & 94.2 \\
\hline Other people & 6 & 3.5 \\
\hline None & 4 & 2.3 \\
\hline Able to pay diabetes treatment & 140 & 81.9 \\
\hline Have health insurance & 170 & 99.4 \\
\hline Smoking & 38 & 22.2 \\
\hline Alcohol use & 138 & 80.7 \\
\hline \multicolumn{3}{|l|}{ Comorbidities } \\
\hline Yes & 159 & 93.0 \\
\hline No & 12 & 7.0 \\
\hline \multicolumn{3}{|l|}{ Body mass index categories } \\
\hline Underweight & 5 & 2.9 \\
\hline Normal & 138 & 80.7 \\
\hline \multirow[t]{2}{*}{ Overweight/obesity } & 28 & 16.4 \\
\hline & Mean & SD \\
\hline Age (years) & 69.4 & 6.8 \\
\hline EQ-5D index & 0.80 & 0.20 \\
\hline VAS & 57.5 & 14.4 \\
\hline
\end{tabular}

Abbreviations: EQ-5D, EuroQol Five Dimensions; VAS, Visual Analog Scale. 
Table 2 Treatment characteristics among respondents

\begin{tabular}{|c|c|c|}
\hline & $\mathbf{n}$ & Percentage \\
\hline \multicolumn{3}{|l|}{ Duration of diabetes } \\
\hline$<$ I year & 7 & 4.1 \\
\hline $\mathrm{I}-5$ years & 35 & 20.5 \\
\hline $6-10$ years & 45 & 26.3 \\
\hline$>10$ years & 84 & 49.1 \\
\hline \multicolumn{3}{|l|}{ Treatment therapy } \\
\hline OAD & 86 & 50.3 \\
\hline Insulin & 25 & 14.6 \\
\hline OAD and insulin & 56 & 32.7 \\
\hline None & 4 & 2.4 \\
\hline \multicolumn{3}{|l|}{ Number of medicines } \\
\hline$<3$ & 28 & 16.4 \\
\hline $3-5$ & 65 & 38.0 \\
\hline \multirow[t]{2}{*}{$>5$} & 78 & 45.6 \\
\hline & Mean & SD \\
\hline Fasting plasma glucose (mmol/L) & 7.7 & 2.2 \\
\hline $\mathrm{HbAlc}(\%)$ & 7.1 & 1.5 \\
\hline
\end{tabular}

Abbreviation: $O A D$, oral anti-diabetic drug.

at home (69.0\%), modified their diet (86.6\%), and always did their exercises $(77.8 \%)$, whereas $42.7 \%$ always monitored their blood pressure at home. Only $3.5 \%$ of patients delayed their examinations and $17.0 \%$ forgot to take their medication in the last 4 weeks (Table 3).

Figure 1 shows the HRQoL status of participants described with the five dimensions of the EQ-5D-3L. One-third of the sample had some problems (level 2) in mobility (33.3\%), whereas $50.9 \%$ and $24.0 \%$ had some problems in

Table 3 Diabetes self-management of respondents

\begin{tabular}{lll}
\hline & $\mathbf{n}$ & Percentage \\
\hline $\begin{array}{l}\text { Self-monitoring blood glucose at home } \\
\text { Yes }\end{array}$ & 118 & 69.0 \\
No & 53 & 31.0 \\
Frequency of blood pressure monitor & & \\
$\quad$ Always (5 times per week or more) & 73 & 42.7 \\
Often (I-4 times per week) & 42 & 24.6 \\
$\quad$ Rarely (I-3 times per month) & 44 & 25.7 \\
Never & 12 & 7.0 \\
Diet modification & & \\
Yes & 148 & 86.6 \\
No & 23 & 13.5 \\
Frequency of doing physical exercises & & \\
5 times per week or more & 133 & 77.8 \\
I-4 times per week & 12 & 7.0 \\
I-3 times per month & 11 & 6.4 \\
Never & 15 & 8.8 \\
Ever delayed examination & & \\
Yes & 6 & 3.5 \\
No & 165 & 96.5 \\
Forgot to take medicine & & \\
Yes & 29 & 17.0 \\
No & 142 & 83.0 \\
\hline
\end{tabular}

pain/discomfort and anxiety/depression, respectively. About $81.3 \%$ of individuals were able to do daily activities in the last 2 weeks and $81.3 \%$ patients felt tired in the last 7 days.

Figure 2 shows the mean VAS score based on age group. The group aged 60-64 years had the highest mean VAS score: $60.1(\mathrm{SD}=13.2)$.

Table 4 presents the factors associated with HRQoL among diabetic patients. In terms of EQ-5D index, patients who were male, living in an urban area, could afford treatment, were taking fewer medications, and often monitored their blood pressure (1-4 times/week) had a higher EQ-5D index compared to others. Meanwhile, higher duration of diabetes and older age were negatively associated with the EQ-5D index. Participants who had any comorbidities had lower VAS scores than their counterparts. Those living in urban areas and taking 3-5 drugs had higher VAS score than those living in rural settings and taking more than 5 drugs, respectively.

\section{Discussion}

Our study was among the first research offering needed insights about the HRQoL of elderly Vietnamese with T2DM. In this study, we found that elderly patients with T2DM had a lower EQ-5D index and VAS score when compared to the general elderly Vietnamese population. ${ }^{35}$ This result was also lower than HRQoL of elderly patients with diabetes in Korea $^{36}$ and India, ${ }^{37}$ but higher than that in Saudi Arabia. ${ }^{38}$ Moreover, our elderly diabetic patients reported substantially high rates of having problems in pain/discomfort, mobility, and anxiety/depression, which align with other studies on Asian populations. ${ }^{21,36,39,40}$

After using multivariate regressions to adjust for sociodemographic characteristics, our results showed that those suffering from comorbidities were more likely to report lower HRQoL, being consistent with worldwide studies. ${ }^{26,27,30,41,42}$ In our cohort, we observed that hypertension and dyslipidemia were the most common comorbidities. Our results also demonstrated that polypharmacy was associated with lower HRQoL. Multiple drugs were often prescribed to patients to manage their T2DM (ie, insulin, anti-hypoglycemic drugs, etc.), comorbid conditions, and related complications. Over-prescription and polypharmacy pose increased risk of adverse drug reactions in the elderly due to physiological changes that result in impaired drug metabolism and excretion. ${ }^{43}$

In addition, we also found that higher duration of diabetes was found to have a significantly negative association with patients' HRQoL, which is consistent with some previous studies. ${ }^{39,44}$ Geriatric syndromes, increasing age, and T2DM 


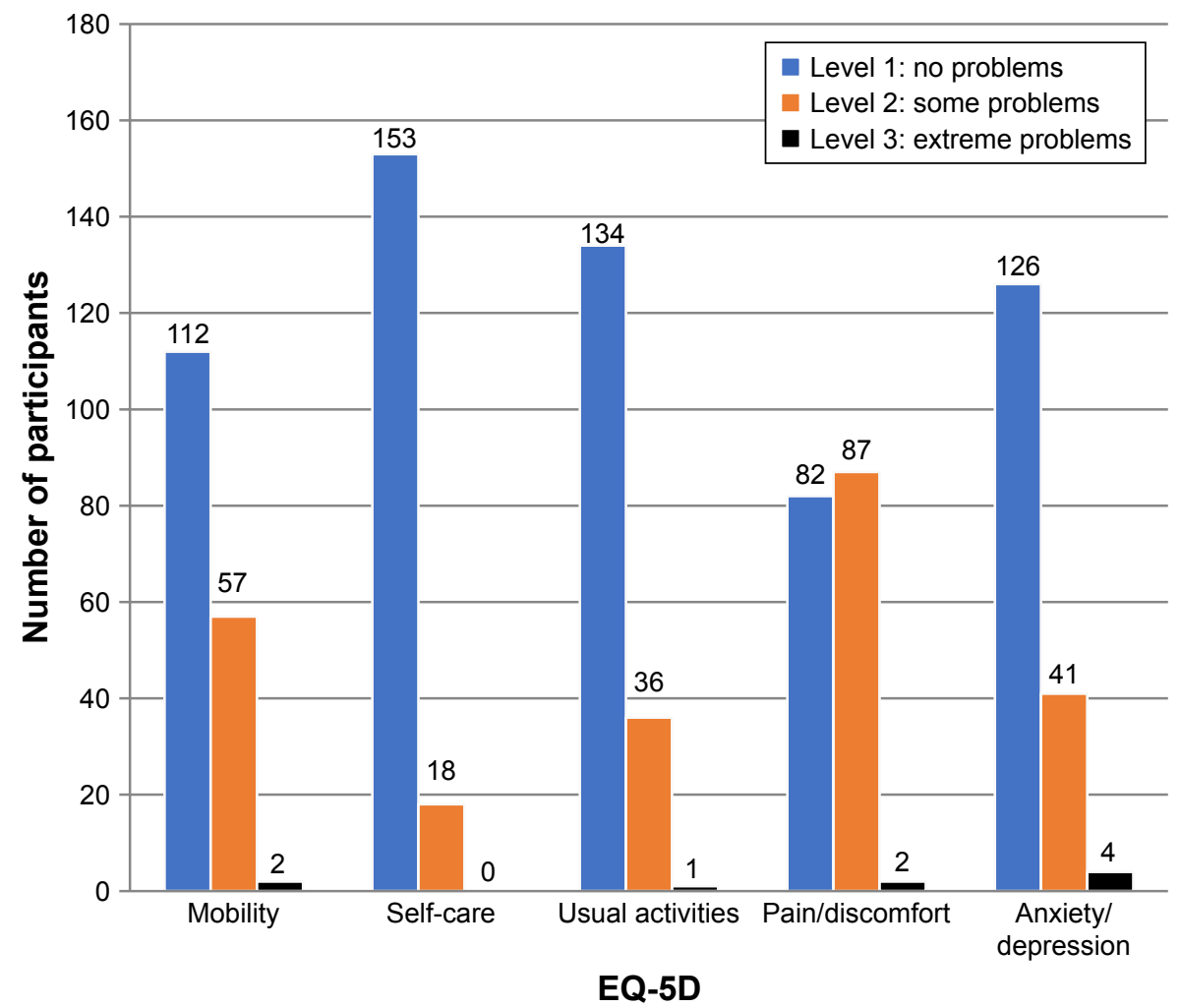

Figure I HRQoL of participants described with the EQ-5D-3L instrument.

Abbreviations: HRQoL, health-related quality of life; EQ-5D-3L, EuroQol Five Dimensions Three Levels.

often require some forms of long-term management and treatment of sequelae, which may compound in those with a longer disease duration. ${ }^{45,46}$ In middle- to low-income countries like Vietnam, management of these chronic conditions places a heavy socioeconomic and emotional burden on both patients and their families. ${ }^{47-49}$ It is likely that our decreased HRQoL in those with a longer disease duration is a combination of compounding comorbidity and complications along with the impact of socioeconomic and emotional burden.

In this study, we found that people with insulin treatment had lower HRQoL compared to those not using any therapies; however, the association was insignificant.

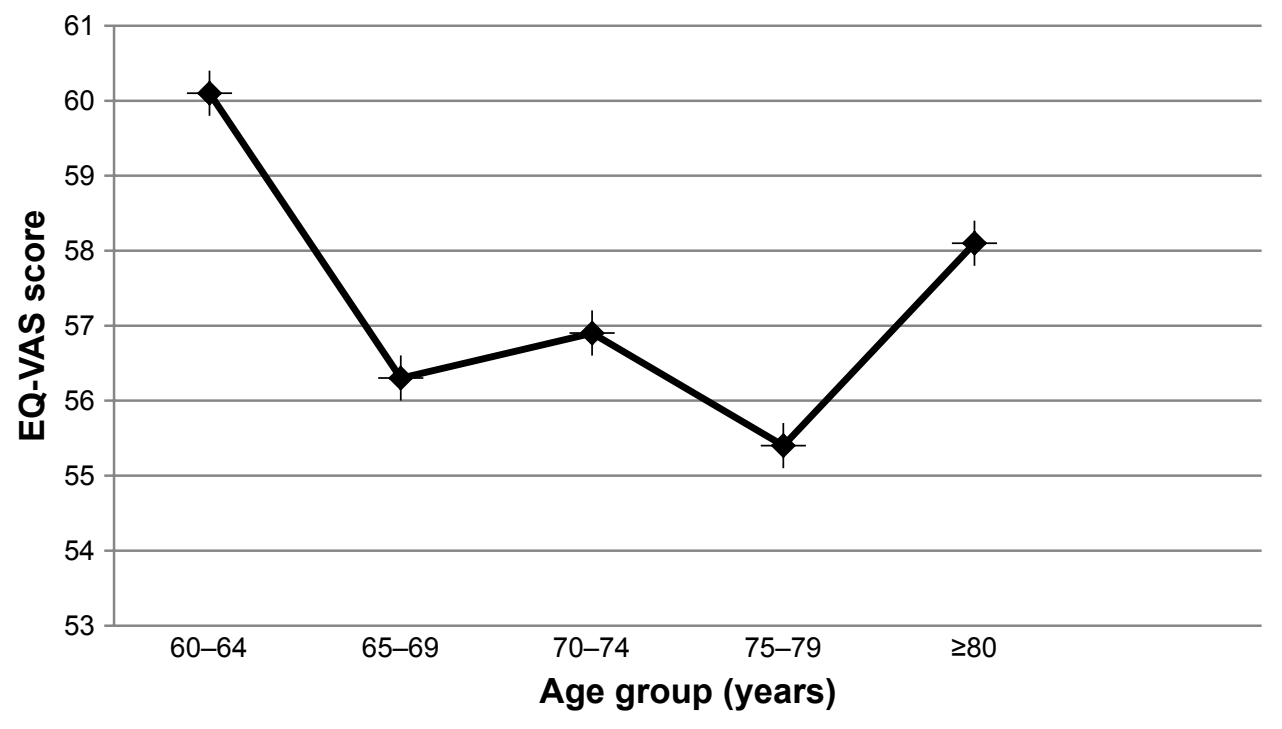

Figure 2 Mean EQ-VAS score for age groups.

Abbreviation: EQ-VAS, EuroQol Visual Analog Scale. 
Table 4 Factors associated with HRQoL among diabetic patients

\begin{tabular}{|c|c|c|c|c|}
\hline & \multicolumn{2}{|c|}{ EQ-5D index } & \multicolumn{2}{|l|}{ VAS } \\
\hline & Coef & $95 \% \mathrm{Cl}$ & Coef & $95 \% \mathrm{Cl}$ \\
\hline Sex (male vs female) & $0.22 *$ & $0.11 ; 0.34$ & 4.80 & $-0.40 ; 10.01$ \\
\hline Age & $-0.0 I^{*}$ & $-0.02 ;-0.00$ & & \\
\hline Living location (urban vs rural) & $0.33^{*}$ & $0.13 ; 0.54$ & $12.13^{*}$ & $1.28 ; 22.98$ \\
\hline Afford diabetic treatment (yes vs no) & $0.16 *$ & $0.0 I ; 0.30$ & & \\
\hline \multicolumn{5}{|l|}{ Duration of diabetes (vs $<$ I year) } \\
\hline $6-10$ years & $-0.14^{*}$ & $-0.25 ;-0.02$ & & \\
\hline \multicolumn{5}{|l|}{ Treatment modalities (vs none) } \\
\hline Insulin & -0.12 & $-0.26 ; 0.01$ & -6.71 & $-13.87 ; 0.45$ \\
\hline \multicolumn{5}{|l|}{ Number of drugs used (vs $>5$ drugs) } \\
\hline$<3$ drugs & $0.23 *$ & $0.08 ; 0.38$ & 5.19 & $-2.22 ; 12.59$ \\
\hline $3-5$ drugs & $0.19 *$ & $0.07 ; 0.30$ & $9.77^{*}$ & $4.14 ; 15.39$ \\
\hline Self-monitoring blood glucose at home (yes vs no) & 0.07 & $-0.04 ; 0.19$ & & \\
\hline Having comorbidities (yes vs no) & & & $-10.16^{*}$ & $-19.00 ;-1.33$ \\
\hline \multicolumn{5}{|l|}{ Frequency of doing exercises (vs none) } \\
\hline I-4 times/week & 0.14 & $-0.05 ; 0.33$ & & \\
\hline Forgot to take medicine (no vs yes) & 0.16 & $-0.07 ; 0.39$ & & \\
\hline \multicolumn{5}{|l|}{ Frequency of monitoring blood pressure (vs none) } \\
\hline I-4 times/week & $0.21 *$ & $0.07 ; 0.34$ & & \\
\hline
\end{tabular}

Note: ${ }^{*} p<0.05$

Abbreviations: HRQoL, health-related quality of life; EQ-5D, EuroQol Five Dimensions; VAS, Visual Analog Scale; Cl, confidence interval.

$\mathrm{Lu}$ et al found that both insulin and oral agent use were associated with lower EQ-5D index scores. ${ }^{44}$ In addition, Luk et al found that insulin use was associated with higher EQ-5D index, but with a lower VAS score, ${ }^{39}$ whereas other work has found that treatment therapies had no impact on HRQoL. ${ }^{21,40,50}$ The lower HRQoL in insulin-treated patients is likely explained by the suffering associated with a heavier burden in patients with more advanced disease, along with the diverse set of complications that come with it. ${ }^{41}$ The difference between our study and other previous studies may be due to the smaller sample size and more advanced age of our cohort. Moreover, Maatouk et al suggested that insulin injections might carry lower stigma in the elderly than in younger adults. ${ }^{30}$ In addition, the lower HRQoL could be caused by the pain of multiple daily insulin injections and the patients' beliefs that taking insulin means the diabetes is worse and the patient has failed. ${ }^{51}$ Therefore, this finding points the need of educational counseling programs for insulin-treated patients from the health staff.

Self-monitoring of blood glucose and hypertension are common home management practices among elderly patients. In this study, we found that frequent monitoring of blood pressure was positively associated with higher HRQoL. Hypertension is both a complication and risk factor of diabetes. ${ }^{13}$ This illness is also a risk factor of other diseases such as stroke and cardiovascular diseases. ${ }^{52}$ Self-monitoring is associated with improved self-care and better treatment compliance, leading to the improvement of health status and HRQoL in patients with chronic diseases. ${ }^{31,53}$

This study has several implications. First, providers of patients with longer disease duration are cognizant of the increased burden faced by those with advanced disease. Interventions focused on improving psychological and emotional wellbeing may improve the HRQoL of patients by addressing important illness and burden-related concerns more common to advanced disease. Second, health care providers should provide education to patients about the importance and effectiveness of self-management practices, such as regular blood pressure and blood glucose monitoring. Moreover, the role of the family in supporting patients in being successful in the self-management of their disease, thereby slowing its advancement, should also be emphasized. Finally, larger future studies should be conducted to fill in the gaps about the HRQoL impact of insulin-related complications among Vietnamese diabetic patients.

There were several limitations to this study. First, its cross-sectional design restricts the drawing of causal relationships between HRQoL and potential associated factors. Second, our use of convenience sampling limits the generalizability of our study to other hospital settings. The effects of recall bias in our data, due to the use of mainly self-reported data, further limit our results. 


\section{Conclusion}

Our study is the first examination of the HRQoL among elderly diabetic patients in Vietnam. Significant decreases in reported HRQoL were related to disease duration, comorbidity, treatment modality, and self-management practices. Screening and identifying health problems in these patients, as well as providing prompt treatment and facilitating self-management, offer low-cost solutions to improving HRQoL in a resource-scarce setting.

\section{Acknowledgments}

The authors gratefully appreciate Ms Dinh Kim Dung and Ms Dao Thi Huyen for helping to recruit patients for this study.

\section{Disclosure}

The authors report no conflicts of interest in this work.

\section{References}

1. World Health Organization. World Report on Ageing and Health. 2015. Available form: http://www.who.int/ageing/events/world-report2015-launch/en/. Accessed November 18, 2017.

2. General Statistics Office of Vietnam. Major findings: the 1/4/2015 time-point population change and family planning. Hanoi: General Statistics Office of Vietnam; 2016.

3. Bussarawan T, Long GT. Socioeconomic status and health among older adults in Vietnam, 2001-2011. In: XXVII IUSSP International Population Conference; August 26-31, 2013; Busan, Republic of Korea.

4. Huong NT, Ha LTH, Tien TQ. Determinants of health-related quality of life among elderly: evidence from Chi Linh Town, Vietnam. Asia Pac J Public Health. 2017;29(5_suppl):84S-93S.

5. George PP, Heng BH, De Castro Molina JA, Wong LY, Wei Lin NC, Cheah JT. Self-reported chronic diseases and health status and health service utilization - results from a community health survey in Singapore. Int J Equity Health. 2012;11:44.

6. Toan NV, Trong LN, Höjer B, Persson LA. Public health services use in a mountainous area, Vietnam: implications for health for policy. Scand J Public Health. 2002;30(2):86-93.

7. Kruk ME, Freedman LP. Assessing health system performance in developing countries: a review of the literature. Health Policy. 2008; 85(3):263-276.

8. Giang KB, Allebeck P. Self-reported illness and use of health services in a rural district of Vietnam: findings from an epidemiological field laboratory. Scand J Public Health Suppl. 2003;62:52-58.

9. Ravens-Sieberer U. Measuring and monitoring quality-of-life in population surveys: still a challenge for public health research. Soz Praventivmed. 2002;47(4):203-204.

10. International Diabetes Federation. IDF Diabetes Atlas. Seventh Edition. 2015. Available from: http://www.diabetesatlas.org/component/attach ments/?task=download\&id=116. Accessed September 23, 2017.

11. Pham NM, Eggleston K. Prevalence and determinants of diabetes and prediabetes among Vietnamese adults. Diabetes Res Clin Pract. 2016;113: $116-124$.

12. Khue NT. Diabetes in Vietnam. Ann Glob Health. 2015;81(6):870-873.

13. Nguyen CT, Pham NM, Lee AH, Binns CW. Prevalence of and risk factors for type 2 diabetes mellitus in Vietnam: a systematic review. Asia Pac J Public Health. 2015;27(6):588-600.

14. Duc Son le NT, Hanh TT, Kusama K, et al. Anthropometric characteristics, dietary patterns and risk of type 2 diabetes mellitus in Vietnam. $J$ Am Coll Nutr. 2005;24(4):229-234.
15. Khan NC, Khoi HH. Double burden of malnutrition: the Vietnamese perspective. Asia Pac J Clin Nutr. 2008;17 Suppl 1:116-118.

16. Ta MT, Nguyen KT, Nguyen ND, Campbell LV, Nguyen TV. Identification of undiagnosed type 2 diabetes by systolic blood pressure and waist-to-hip ratio. Diabetologia. 2010;53(10):2139-2146.

17. Mwangi J, Kulane A, Van Hoi L. Chronic diseases among the elderly in a rural Vietnam: prevalence, associated socio-demographic factors and healthcare expenditures. Int J Equity Health. 2015;14:134.

18. Paolisso G. Pathophysiology of diabetes in elderly people. Acta Biomed. 2010;81 Suppl 1:47-53.

19. Kesavadev JD, Short KR, Nair KS. Diabetes in old age: an emerging epidemic. J Assoc Physicians India. 2003;51:1083-1094.

20. Croxson SC, Price DE, Burden M, Jagger C, Burden AC. The mortality of elderly people with diabetes. Diabet Med. 1994;11(3):250-252.

21. Choi YJ, Lee MS, An SY, et al. The relationship between diabetes mellitus and health-related quality of life in Korean adults: the Fourth Korea National Health and Nutrition Examination Survey (2007-2009). Diabetes Metab J. 2011;35(6):587-594.

22. Kanauchi M, Kubo A, Kanauchi K, Saito Y. Frailty, health-related quality of life and mental well-being in older adults with cardiometabolic risk factors. Int J Clin Pract. 2008;62(9):1447-1451.

23. Lin CC, Li CI, Chang CK, et al. Reduced health-related quality of life in elders with frailty: a cross-sectional study of community-dwelling elders in Taiwan. PLoS One. 2011;6(7):e21841.

24. Nezu S, Okamoto N, Morikawa M, et al. Health-related quality of life (HRQOL) decreases independently of chronic conditions and geriatric syndromes in older adults with diabetes: the Fujiwara-kyo Study. J Epidemiol. 2014;24(4):259-266.

25. Tang WL, Wang YM, Du WM, Cheng NN, Chen BY. Assessment of quality of life and relevant factors in elderly diabetic patients in the Shanghai community. Pharmacoepidemiol Drug Saf. 2006;15(2):123-130.

26. Ghassemzadeh R, Nasseh H, Arastoo AA, Kamali M, Rahimi Foroushani A, Arzaghi M. Quality of life in elderly diabetic: comparison between home and nursing home. Acta Med Iran. 2013;51(4): 254-259.

27. Trief PM, Wade MJ, Pine D, Weinstock RS. A comparison of healthrelated quality of life of elderly and younger insulin-treated adults with diabetes. Age Ageing. 2003;32(6):613-618.

28. Ausili D, Bulgheroni M, Ballatore $\mathrm{P}$, et al. Self-care, quality of life and clinical outcomes of type 2 diabetes patients: an observational crosssectional study. Acta Diabetol. 2017;54(11):1001-1008.

29. Trikkalinou A, Papazafiropoulou AK, Melidonis A. Type 2 diabetes and quality of life. World J Diabetes. 2017;8(4):120-129.

30. Maatouk I, Wild B, Wesche D, et al. Temporal predictors of healthrelated quality of life in elderly people with diabetes: results of a German cohort study. PLoS One. 2012;7(1):e31088.

31. Gilden JL, Casia C, Hendryx M, Singh SP. Effects of self-monitoring of blood glucose on quality of life in elderly diabetic patients. $J \mathrm{Am}$ Geriatr Soc. 1990;38(5):511-515.

32. Brown DW, Balluz LS, Giles WH, et al; Behavioral Risk Factor Surveillance System (BRFSS). Diabetes mellitus and health-related quality of life among older adults. Findings from the behavioral risk factor surveillance system (BRFSS). Diabetes Res Clin Pract. 2004;65(2):105-115.

33. Group E. EQ-5D-3L User Guide: Basic information on how to use the EQ-5D-3L instrument. 2015. Available from: https://euroqol.org/wpcontent/uploads/2016/09/EQ-5D-3L_UserGuide_2015.pdf. Accessed January 6, 2017.

34. American Diabetes Association. Standards of medical care in diabetes 2017. Diabetes Care. 2017;40(1):48-57.

35. Bang KS, Tak SH, Oh J, Yi J, Yu SY, Trung TQ. Health status and the demand for healthcare among the elderly in the rural Quoc-Oai District of Hanoi in Vietnam. Biomed Res Int. 2017;2017:4830968.

36. Lee WJ, Song KH, Noh JH, Choi YJ, Jo MW. Health-related quality of life using the EuroQol 5D questionnaire in Korean patients with type 2 diabetes. J Korean Med Sci. 2012;27(3):255-260. 
37. Singh K, Kondal D, Shivashankar R, et al. Health-related quality of life variations by sociodemographic factors and chronic conditions in three metropolitan cities of South Asia: the CARRS study. BMJ Open. 2017;7(10):e018424.

38. Al-Aboudi IS, Hassali MA, Shafie AA. Knowledge, attitudes, and quality of life of type 2 diabetes patients in Riyadh, Saudi Arabia. J Pharm Bioallied Sci. 2016;8(3):195-202.

39. Luk AOY, Zhang Y, Ko GTC, et al. Health-related quality of life in Chinese patients with type 2 diabetes: an analysis of the Joint Asia Diabetes Evaluation (JADE) Program. J Diabetes Metab. 2014;5:333.

40. Sakamaki H, Ikeda S, Ikegami N, et al. Measurement of HRQL using EQ-5D in patients with type 2 diabetes mellitus in Japan. Value Health. 2006;9(1):47-53.

41. Wändell PE, Tovi J. The quality of life of elderly diabetic patients. J Diabetes Complications. 2000;14(1):25-30.

42. Sakurai T, Iimuro S, Sakamaki K, et al; Japanese Elderly Diabetes Intervention Trial Study Group. Risk factors for a 6-year decline in physical disability and functional limitations among elderly people with type 2 diabetes in the Japanese Elderly Diabetes Intervention Trial. Geriatr Gerontol Int. 2012;12 Suppl 1:117-126.

43. Milton JC, Hill-Smith I, Jackson SH. Prescribing for older people. BMJ. 2008;336(7644):606-609.

44. Lu Y, Wang N, Chen Y, et al. Health-related quality of life in type-2 diabetes patients: a cross-sectional study in East China. BMC Endocr Disord. 2017;17(1):38.

45. Li MZ, Ji LN, Meng ZL, et al. Management status of type 2 diabetes mellitus in tertiary hospitals in Beijing: gap between guideline and reality. Chin Med J (Engl). 2012;125(23):4185-4189.
46. Stolar MW, Hoogwerf BJ, Gorshow SM, Boyle PJ, Wales DO. Managing type 2 diabetes: going beyond glycemic control. J Manag Care Pharm. 2008;14(5 Suppl B):s2-s19.

47. Gallacher K, May CR, Montori VM, Mair FS. Understanding patients' experiences of treatment burden in chronic heart failure using normalization process theory. Ann Fam Med. 2011;9(3):235-243.

48. Sav A, Salehi A, Mair FS, McMillan SS. Measuring the burden of treatment for chronic disease: implications of a scoping review of the literature. BMC Med Res Methodol. 2017;17(1):140.

49. Sav A, King MA, Whitty JA, et al. Burden of treatment for chronic illness: a concept analysis and review of the literature. Health Expect. 2015;18(3):312-324.

50. Mayberry LS, Osborn CY. Family support, medication adherence, and glycemic control among adults with type 2 diabetes. Diabetes Care. 2012;35(6):1239-1245.

51. Fremantle N, Blonde L, Duhot D, et al. Availability of inhaled insulin promotes greater perceived acceptance of insulin therapy in patients with type 2 diabetes. Diabetes Care. 2005;28(2):427-428.

52. World Health Organization. Hypertension. 2017. Available from: http:// www.who.int/topics/hypertension/en/. Accessed November 18, 2017.

53. Watts FN. Behavioural aspects of the management of diabetes mellitus: education, self-care and metabolic control. Behav Res Ther. 1980;18(3): 171-180.
Patient Preference and Adherence

\section{Publish your work in this journal}

Patient Preference and Adherence is an international, peer-reviewed, open access journal that focuses on the growing importance of patient preference and adherence throughout the therapeutic continuum. Patient satisfaction, acceptability, quality of life, compliance, persistence and their role in developing new therapeutic modalities and compounds to optimize

\section{Dovepress}

clinical outcomes for existing disease states are major areas of interest for the journal. This journal has been accepted for indexing on PubMed Central. The manuscript management system is completely online and includes a very quick and fair peer-review system, which is all easy to use. Visit http://www. dovepress.com/testimonials.php to read real quotes from published authors. 